\title{
English Economic Discourse in Translation Studies
}

\author{
Irina Zaykova* \\ Irkutsk National Research Technical University, Foreign Languages Department, 664074, Irkutsk, Russia
}

\begin{abstract}
The article aims to study English economic discourse from the theory of translation. Theoretical analysis shows that it is a process of communication between participants in various fields of professional activity. It is also characterized by the presence of certain extralinguistic features (source / author and recipient / addressee, etc.), as well as the features of its result economic text. This kind of text is diverse in style and genre, and contains professionally relevant and terminologically expressed branch information. To expand the interpretation, English economic discourse is studied as an object of translation activity. It is a special kind of discursive practices that can be possible between an agent and a client, professional journalists and ordinary listeners / readers or non-specialist journalists (Discourse of Differences, Discourse of Concord), between professional journalists, scientists, lecturers, researchers (Discourse of Expert Community). The study reveals frequent genres of economic texts in translation activity. The survey carried out in different organizations shows that the translation activity deals with commercial documents and correspondence, scientific articles and reports.
\end{abstract}

\section{Introduction}

The study of discourse occupies a central place in linguistic researches since the end of the 20th century. Scholars give numerous interpretations to this phenomenon, study its theoretical and applied problems, the ratio of verbal and extralinguistic ones in it [1-7].

Despite a large number of scientific works devoted to discourse, the questions of defining discourse and its classification, in particular its species, still remain relevant.

In translation theory, the term "discourse" has recently appeared in a linguistic, cultural and literary discourse. The discourse study, which is of undoubted interest as the knowledge of original discourse, influences directly the creation of a translation product. It helps to comprehend more deeply the object, and the process of translation activity. The analysis of discourse is an important part of translation activities. In translation, discourse - analysis is a way out of the translated text and consideration of its links with other texts.

Economic discourse serves as an object of numerous studies due to the urgency of issues discussed in the international economic arena: globalization of economy, entry of Russia into the world economic space, assistance to underdeveloped countries, etc. [8-13]. In this regard, the study of English economic discourse from the perspective of translation theory is highly relevant.

Analysis shows that no attempts have been made to formulate the definition of the concept of "Economic discourse" as a translation object. Only its features as an object of linguistic research are still under study [10-13]. In addition, the species boundaries of the term in translation theory have not been clearly defined yet. The authors only study the linguistic features of economic discourse from the point of view of relationship to one or another sphere of the economy. In particular, much attention is paid to the study of semantic and syntactic aspects of German economic discourse [9, 10, 12]. So far, the features of English economic discourse as an object of translation activity have not been studied. The article aims to identify its features as a linguistic phenomenon, as well as to reveal its specificity from the point of view of translation activity.

\section{English Economic Discourse Linguistic Phenomenon}

As the analysis shows, discourse is a complex object with an indefinitely defined concept in modern linguistics. It is explained by the conditions for the formation and existence of this term, and the uncertainty of discourse place in the system of language categories.

In wide sense, discourse is a communicative event occurring between a speaker and an attendant in the process of communicative action at a certain time, space and time context. This communicative action can be verbal, written and non-verbal. In narrow sense, discourse is regarded as a text or a conversation [14].

It should be noted that discourse and text are delineated according to a number of criteria. Discourse is a complex communicative phenomenon that includes

* Corresponding author: irazaykova@mail.ru 
extralinguistic factors: knowledge about the world, opinions, attitudes, goals of the addressee [15].

Discourse is a communicative phenomenon that includes the author, the text and the recipient in the activity of constructing and understanding meanings against the background of the social and cultural context [16].

Unlike discourse, the text is the result of speech activity. It is related to the context and its cognitive evaluation on the part of participants in communication. They determine the content of the text and organize its multi-layered structure [17]. Consequently, the text is a result of participants' communicative activities and an instrument of social interaction [18].

Thus, it is possible to conclude that the difference between discourse and text is that discourse is understood as communicative activity, as a process, while the text is its result. Needless to say that discourse is a speech immersed in life or the text, immersed in the situation of communication [7]. It means that discourse is relevant in time; the text does not depend on time [19, 20].

Thus, text has significant differences from the discourse. On the other hand, these two concepts have a number of similar characteristics. Both text and discourse have their own users: the author and the reader as well as the author of discourse who performs a certain role (social, communicative, etc.) [21].

Thus, the text and discourse turn out to be related "cause-and-effect relations". At the same time, discourse is a broader concept than text [22]. Extrapolating obtained data to research object, it can be concluded that the economic discourse is a process of communicative activity, and English economic text is its result.

In scientific literature, economic discourse is considered as a process of creating texts in conjunction with socio-cultural, psychological and pragmatic factors. It is also a purposeful social action that involves people's interaction and cognitive mechanisms of their consciousness [8]. In addition, it is defined as a set of speech acts in the sphere of economy in the form of oral and written texts reflecting the realities of economic world [13]. Thus, economic discourse is characterized by the presence of certain extralinguistic features, as well as the features of economic text.

Concerning extralinguistic characteristics, it should be noted that the participants of discourse play a special role. E. Benveniste says that the essential feature of discourse is its correlation with specific participants in the communicative act [23]. The participants of economic discourse are also one of its main characteristics [10]. The economy covers a wide range of activities: business, finance and credit, accounting and audit, tax and insurance, and trade. Therefore, the participants of English economic discourse are specialists in different spheres of activity.

Economic text has special linguistic parameters. It is characterized by a variety of styles and genres [24]. Economic texts correlate with the texts of official business style. According to the researchers, the official business style constitutes a macro-environment of verbal communication in the sphere of purely formal human relationships [25]. It is possible to refer economy to this area. Commercial documents and correspondence can be called as economic texts of official business style.

The newspaper style covers the texts in which the events and phenomena in the field of economy are reported i.e. newspaper articles on economic subjects.

As for the scientific style, the practice shows that economic texts are presented as scientific articles, reports and monographs (See Table 1).

Table 1. Economic texts.

\begin{tabular}{|c|c|}
\hline Functional Styles & Economic Texts \\
\hline Official business style & $\begin{array}{c}\text { Commercial documents } \\
\text { and correspondence }\end{array}$ \\
\hline Newspaper style & Newspaper articles \\
\hline Scientific style & $\begin{array}{c}\text { Articles, reports and } \\
\text { monographs }\end{array}$ \\
\hline
\end{tabular}

In addition, economic text is characterized by professionally significant and terminologically expressed industry information. S. Vlasenko points out that any special text is a text, that is difficult for non-specialists to perceive, the text in which the subject knowledge is presented [26].

The text of commercial document below shows the extract from agreement. It demonstrates a lot of brunch information and terms:

\section{AGREEMENT $^{1}$}

ALL EUROPEAN TRAVEL Ltd., hereafter referred to as ALL EUROPEAN TRAVEL, on the one part, and

on the other part, have concluded the present contract to the following effect:

\section{SUBJECT MATTER OF CONTRACT}

ALL EUROPEAN TRAVEL provides services (hotel accommodation, transfers, itineraries, programs, visa support) to the tourist groups and individual tourist from...................... sent

by................... , who undertakes to sell out to the United Kingdom, arranging, at its own expense, the necessary advertising on its territory.

\section{ITINERARIES, PROGRAMMES, PRICES}

a) The conditions and prices will be specifically agreed upon, with each individual case in writing by either e-mail or fax.

b) Any revisions in itineraries, programs and prices of tours will be agreed upon by the parties in writing by either e-mail or fax.

3. PRICES AND TERMS OF PAYMENT

a) The prices of services will be fixed in UK $£$ Sterling.

b) The payment for the confirmed tourists and

\footnotetext{
${ }^{1}$ Some data are changed and missed for confidentiality.
} 
transport services will be effected in UK $£$

Sterling when possible; otherwise payment in US dollars will be accepted at the prevailing rate of exchange.

c) will effect all the payments by bank remittance to $: . . . . .$.

Bank account in ........

The following text contains mainly terms:

\section{INCOME STATEMENTS ${ }^{2}$ \\ (In millions, except per share amounts)}

Three Months Ended September 30,

$2016 \quad 2015$

\begin{tabular}{|c|c|c|}
\hline \multicolumn{3}{|l|}{ Revenue: } \\
\hline$\underline{\text { Product }}$ & $\$ 13.493$ & $\$ 15.219$ \\
\hline$\underline{\underline{S e r v i c e} \text { and other }}$ & 6.960 & 5.160 \\
\hline Total revenue & 20.453 & 20.379 \\
\hline \multicolumn{3}{|l|}{ Cost of revenue: } \\
\hline$\underline{\text { Product }}$ & 3.581 & 4.035 \\
\hline$\underline{\text { Service and other }}$ & 4.263 & 3.172 \\
\hline Total cost of revenue & 7.844 & 7.207 \\
\hline$\underline{\text { Gross margin }}$ & 12.609 & 13.172 \\
\hline
\end{tabular}

Practice shows, except terms, English economic text is rich in abbreviations, acronyms (GDP, VAT, IMF, NYSE, WTO, CPI, NASDAQ, NAFTA, ASE, CEO), lexicon (a drive-in-bank, to clock in, stop -go-stop policy, shoeleather costs, teleworking, a chain store, a self-made man) and unique cultural realities ("Great Depression, Four Freedoms, Sexual Harassment in the Workplace").

Summarizing all above-mentioned, it can be concluded that English economic discourse is a process of communication between participants in various fields of professional activity, resulting in the text that is diverse in style and genre, and the availability of professionally relevant and terminologically expressed brunch information.

This interpretation is important for understanding English economic discourse as an object of translational research. To expand the interpretation of concept, it should be studied as an object of translation activity.

\section{English Economic Discourse in Translation Activity}

${ }^{2} \mathrm{URL}:$ https://www.microsoft.com/enus/Investor/earnings/FY-2017-Q1/press-release-webcast (date access: 12.04.18).
Translation activity is a special kind of discursive practice in which translator forms intercultural interlingual discourse. The translator acts as a discourse agent, an expert in intercultural communication, a mediator between worlds and cultures, a language consultant, and a specialist in the field of a different culture [27, 28].

Thus, a translator becomes a member of a certain "discursive community". This term became popular due to J. Swales. The author points out that a discursive community is a group of people engaged in common activities, having common interests and their own communication mechanisms. They use certain speech genres to express its communicative goals and have a special vocabulary [29].

In other words, the members of the discursive community are linked by communicative goals, terminology, a level of competence in a certain field of activity, knowledge of genre organization and mechanisms of its exchange. It is also a special institutionalized type of thinking [30]. Wherein, the translation activity can be considered as discursive practices of various kinds [27].

A. Kaplunenko suggests the division of discursive practices into Discourse of Differences, Discourse of Concord and Discourse of Expert Community. The Discourse of Differences assumes different points of view on the problem. The participants have to overcome these differences in the process of interaction, or strengthen them, forming stable conflict zones of speech activity [31]. It should be taken into account that the Discourse of Differences is not an absolute conflict and a global misunderstanding. It is a process of identification of universal features [32: 147].

Discourse of Concord is the stage when participants seek to establish a common point of view, at least in vital areas of activity [32: 147]. Discourse of Expert Community supposes the stage when participants are united by professional goals. The have special knowledge for handling professional issues, generating expert opinions and ideas using professional terminology [32: 148].

English economic discourse practices can be observed in a base pair "agent-client" [10]. The agent is a legal entity (organization, bank and individual entrepreneur) and the customer can be an individual (ordinary buyer, or legal entity: organization, bank or individual entrepreneur). Thus, both Discourse of Differences and Discourse of Concord can occur in these discursive practices. The Discourse of Expert Community is obviously possible only between legal entities.

Similar logic of the mentioned types of discourse is observed in a pair of journalists - professionals. Discourse of Differences, as well as Discourse of Concord can be existed between professional journalists and ordinary listeners / readers of news about economic events or professional journalists and non-specialist journalists. They are presented in newspaper and magazine articles on economic subjects.

Discourse of Expert Community is possible between professional journalists, lecturers, scientists, researchers 
and students - specialists in a certain field of economics. This discourse is reflected in scientific economic texts.

Thus, English economic discourse covers a wide range of discursive practices. It obviously influences the methods and techniques that can be used by a specialist in the process of translation activity (See Figure 1).

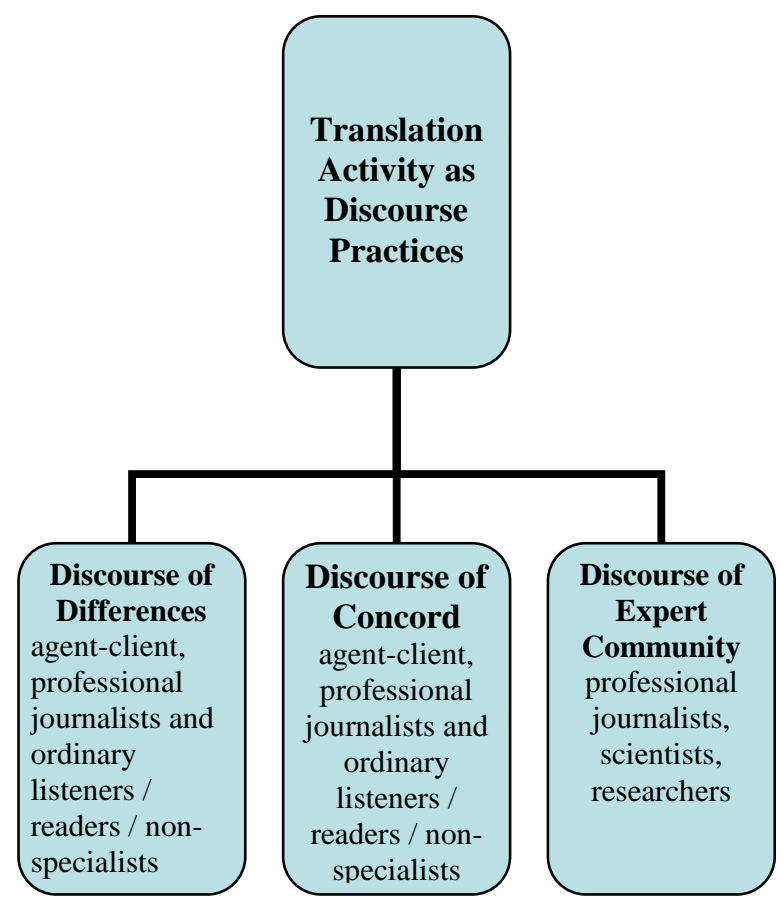

Fig. 1 Translation activity as discursive practices.

The survey was carried out due to revealing the frequent genres of English economic texts in translation activity. Twenty translators in Irkutsk were interviewed at various enterprises / firms / institutions and organizations. Specialists were asked to point out the genres of economic texts they deal with.

The survey shows that professional activity of a translator is mainly connected with the work at an enterprise or firm, where he is the only specialist who regulates the information flow of all kinds from foreign sources. Enterprises or firms cooperate with foreign partners in business negotiations. The translator deals with commercial documents, as well as with different types of correspondence.

Eighteen translators confirmed that they had to work with contracts, agreements, financial reports, informative letters, invoices, orders and advertising letters.

Fifteen respondents stated that except business documents, they deal with press releases, as well as with the articles from magazines and newspapers. This is due to the fact that the enterprise or firm needs to analyze important consumer-relevant information that can sometimes be in a $\mathrm{f}$

According to the survey, twelve respondents answered that their professional activities are connected with translation of scientific articles and reports on economics. This tendency is based on the involvement of a large number of countries in the process of intercultural scientific communication. It is characterized by globalization of the world economy that is convergence of business and consumer culture around the world, growth of international communication, world division of labor, and migration of labor.

All in all, translation activity covers all genres of economic texts. The most frequent of them are commercial documents and correspondence, scientific articles and reports are in the third place (Figure2).

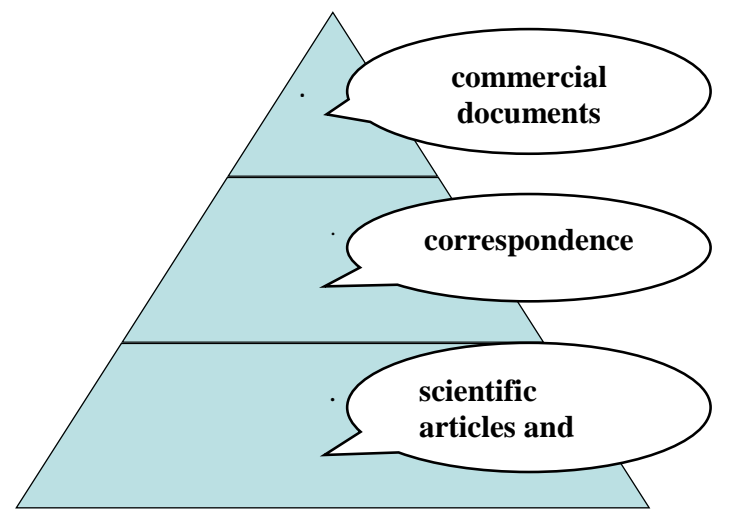

Fig. 2 Economic texts in translation activity.

\section{Conclusion}

Theoretical analysis shows that English economic discourse is a process of communicative activity in various spheres of communication. Its specificity is due to participants and peculiarities of economic text. This text is rich in branch terminology, various genres and styles. As an object of translation activity, English economic discourse implies discursive practices. They are rather variable. They are carried out between an agent and a client, professional journalists and ordinary listeners / readers, professional journalists and nonspecialist journalists (Discourse of Differences, Discourse of Concord). Also, it can be observed between professional journalists or experts in economics (Discourse of Expert Community).

According to the survey carried out in different organizations, the translation activity deals with commercial documents and correspondence, newspaper and magazine articles, scientific articles and reports. Commercial documents (contracts / agreements, financial reports, etc.) and correspondence are the most frequent genres.

Studied features of English economic discourse will serve as a basis for further research of translation from English into Russian. It will help to understand and reveal mechanisms of the translation process as a complex multidimensional phenomenon, creation of theoretical models of translation and description of different types of transformations.

\section{References}


1. H. Clark, E.Schaefer, Cognitive Science 13, 259294 (1989)

2. M. Alvesson, D. Karreman, Human Relations $\mathbf{5 3}$ (9), 1125-1149 (2000)

3. B.a Benwell, E.Stokoe, Discourse and identity (University of Stirling, United Kingdom, Department of Social Sciences, Loughborough University, 2006)

4. C. Hardy, I. Palmer, N. Phillip, Human Relations 53 (9), 1227-1248 (2000)

5. T.A. Van Dijk, Society and Discourse: How Social Contexts Influence Text and Talk (Department of Translation and Philology, Pompeu Fabra University, Barcelona, 2009)

6. T.A. Van Dijk, Discourse and Context: A Sociocognitive Approach (Department of Translation and Philology, Pompeu Fabra University, Barcelona, 2008)

7. V.I. Karasik, Language Circle: Personality, Contexts, Discourse (Gnosis, Moscow, 2004).

8. E.Yu. Voyakina, Onomastic Metaphor in the Economic Discourse (Tambov State Technical University, Tambov, 2014)

9. L.M. Shakiryanov, European social science journal 11-1 (38), 210-218 (2013)

10. A.A. Sheremetyeva, I.N. Zyryanova, Siberian Philological Journal 4, 152-161 (2016)

11. K.W. Tomashevskaya, The lexical component of the economic discourse of a contemporary (Indrik, Moscow, 2004)

12. S.V. Chertousova, Evolution and transformation of Discourse, 145-152 (2016)

13. T.A. Evtushina, N.A. Kovalskaya, Vestnik of Chelyabinsk State University 6, 42-44 (2014).

14. T.A. Van Dijk, Ideology: A Multidisciplinary Approach (Sage, London, 1998)

15. Yu.N. Karaulov, Russian language and language personality (Science, Moscow, 1989)

16. C. Kramsh, Language and Culture (Oxford University Press, Oxford, 1998)

17. W. Heinemann, D. Viehweger, Textlinguistik: Eine Einführung (Niemeyer, Tübingen, 1991)

18. O.A. Krapivkina, Tomsk State University Journal of Philology 46, 21-30 (2017)

19. N.D. Arutyunova, The Proposition and Its Meaning (Knowledge, Moscow, 1990)

20. A.A Zalevskaya, Psycholinguistic studies. Word. Text (Gnosis, Moscow, 2005)

21. T.V. Drozdova, Problems of Understanding the Scientific Text (Astrakhan State Technical University, Moscow, 2003)

22. E.S. Kubryakova, Functional and structural aspects, 7-25 (2000)

23. E. Benveniste, General Linguistics (Editorial URSS, Moscow, 2009)
24. I.V. Zaykova, Modeling the economic macrodiscourse in teaching translation to university students (Irkutsk National Research Technical University, Irkutsk, 2017)

25. M.P. Brandes, V.I. Provotorov, Pretranslation text analysis (for institutes and faculties of foreign languages) (Rosi, Kursk, 2001)

26. S.V. Vlasenko, Contract Law: Professional Translation practices in the English-Russian Language Pair (Wolters Clover, Moscow, 2006)

27. A.A. Gureeva, E.Y. Novikova V.A. Mitygina, Xlinguage 9 (2), 90-102 (2016)

28. E.Yu. Novikova, Vestnik of Volgograd State University, a series of linguistics 16 (3), 90-102 (2017)

29. J.M. Swales, Genre Analysis: English in Academic and Research Settings (Cambridge Univ. Press, Cambridge, 1990)

30. O.A. Krapivkina, Siberian Philological journal1 1, 137-143 (2016)

31. A.M. Kaplunenko, Vestnik of Irkutsk State Linguistic University 2s (18), 16-21 (2012)

32. O.A. Krapivkina, ASSEHR 97, 146-151 (2017) 